\title{
AVALIAÇÃO DA APRENDIZAGEM DA LÍNGUA JAPONESA DO PONTO DE VISTA MOTIVACIONAL
}

\author{
Clara Yoshiko Hori Takigawa
}

Engenharia de Produção - FEPP - UNOESTE. E-mail: clarahori@unoeste.br

\begin{abstract}
RESUMO
A intensidade e a qualidade do envolvimento do aluno necessário para aprender, na maioria das vezes, estão relacionadas à sua motivação. O presente estudo é uma pesquisa qualitativa e quantitativa que teve como objetivo verificar a relação entre a motivação e o desempenho na avaliação da aprendizagem da língua japonesa nos alunos concluintes de um centro de estudo de línguas de Presidente Prudente-SP, assim como, se há uma relação com a etnia destes alunos. Constatou-se que a quantidade e a intensidade dos fatores que motivam o aluno são importantes no processo de aprendizagem dos alunos, pois de alguma forma refletem no seu desempenho nas avaliações realizadas. Foi constatado também que não há uma relação direta entre a antecedência racial do aluno com a motivação dele no processo de aprendizagem e também com o seu desempenho nas avaliações realizadas no curso.
\end{abstract}

Palavras-chave: Motivação. Avaliação. Aprendizagem. Língua japonesa.

\section{INTRODUÇÃO}

A motivação é considerada um aspecto muito importante no processo de aprendizagem de uma língua estrangeira, pois a intensidade e a qualidade do envolvimento do aluno necessário para aprender, na maioria das vezes, estão relacionadas à sua motivação.

Acompanhar o processo de aprendizagem através de avaliações é uma prática pedagógica tradicional na educação que pode trazer grandes benefícios quando se torna uma ferramenta auxiliadora do professor para verificar o progresso do aluno e quando desencadeia em todos os participantes deste processo uma reflexão do ensino e da aprendizagem.

O presente estudo tem como objetivo verificar a relação entre a motivação e o desempenho na avaliação da aprendizagem da língua japonesa nos alunos concluintes de um centro de estudo de línguas de Presidente Prudente-SP, assim como, analisar essas informações sob a perspectiva da antecedência racial dos alunos pesquisados.

Este estudo possibilitará verificar ou desfazer alguns mitos sociais e culturais referente ao ensino e aprendizagem da língua japonesa, tais como, os alunos descendentes de japoneses são mais motivados no aprendizado da língua japonesa, ou, ou alunos não descendentes de japoneses tem maior dificuldade no aprendizado da língua japonesa. 


\section{METODOLOGIA}

Esta pesquisa é um estudo de caso, pois tem como objetivo investigar um fenômeno contemporâneo dentro de um contexto da vida real utilizando múltiplas fontes de evidências (YIN, 2010, p. 23).

O presente estudo focaliza o ambiente escolar, familiar e outros contextos sociais como possíveis promotores das motivações dos alunos aprendizes da língua japonesa, baseando-se nos fundamentos da investigação qualitativa. Este estudo também é uma pesquisa quantitativa, pois traduz em números as informações para classificá-las e analisá-las.

Do ponto de vista de seus objetivos é uma pesquisa exploratória, pois visa maior familiaridade com o problema tornando-o explicito.

Este estudo não terá o intuito de generalizar os resultados, mas sim, a compreensão do funcionamento de um determinado grupo em um determinado contexto.

Essa pesquisa foi realizada com o curso de língua japonesa de um centro de estudo de línguas localizado na cidade de Presidente Prudente-SP. A professora responsável pela turma pesquisada forneceu o questionário aplicado por ela para verificar as motivações dos alunos no aprendizado da língua japonesa, assim como, disponibilizou o seu diário de classe com as notas das diversas avaliações de aprendizagem dos respectivos alunos, referente ao segundo semestre de 2012.

Os alunos participantes desta pesquisa são 15 alunos regulamente matriculados no último estágio do curso, 3o estágio-nível II, que estão sendo identificados nesta pesquisa como A1(aluno 1), A2 (aluno 2), A3 (aluno 3), ..., A15 (aluno 15).

Dos alunos participantes, 07 alunos são descendentes de pai e mãe japoneses, 06 alunos são descendentes de mãe ou pai japoneses e 02 alunos não são descendentes de japoneses. A faixa etária desses alunos é de 13 a 18 anos de idade. Desses alunos 09 são do sexo feminino e 06 são do sexo masculino.

\section{RESULTADOS}

\subsection{Análise do perfil motivacional dos alunos}

As perguntas do questionário que estavam relacionadas às motivações dos alunos no aprendizado foram pontuadas, considerando que cada resposta "sim" é um fator que motiva o aluno no aprendizado da língua japonesa. A somatória dos pontos possibilitou classificar os alunos quanto ao seu grau motivacional (Quadro 1). 
QUADRO 1. Motivação dos alunos no aprendizado da língua japonesa

\begin{tabular}{|c|c|c|c|}
\hline $\begin{array}{c}\text { Identificação dos } \\
\text { alunos }\end{array}$ & Descendência & $\begin{array}{c}\text { Motivação } \\
\text { (pontos) }\end{array}$ & Classificação \\
\hline A1 & Brasileira & 8 & $\mathrm{M}$ \\
\hline A2 & Japonesa & 9 & $\mathrm{M}$ \\
\hline A3 & Brasileira/Japonesa & 12 & $\mathrm{MM}$ \\
\hline A4 & Japonesa & 7 & $\mathrm{PM}$ \\
\hline A5 & Japonesa & 4 & $\mathrm{PM}$ \\
\hline A6 & Brasileira/Japonesa & 10 & $\mathrm{M}$ \\
\hline A7 & Japonesa & 8 & $\mathrm{M}$ \\
\hline A8 & Brasileira & 10 & $\mathrm{M}$ \\
\hline A9 & Brasileira/Japonesa & 5 & $\mathrm{PM}$ \\
\hline A10 & Brasileira/Japonesa & 8 & $\mathrm{M}$ \\
\hline A11 & Brasileira/Japonesa & 10 & $\mathrm{M}$ \\
\hline A12 & Brasileira/Japonesa & 9 & $\mathrm{M}$ \\
\hline A13 & Japonesa & 8 & $\mathrm{M}$ \\
\hline A14 & Japonesa & 6 & $\mathrm{PM}$ \\
\hline A15 & Japonesa & 13 & $\mathrm{MM}$ \\
\hline
\end{tabular}

A quantidade de fatores que podem motivar o aluno no aprendizado da língua japonesa estabelecida no questionário aplicado possibilita a variação de 0 a 17 pontos. Desta forma, quanto maior a pontuação do aluno maior é a quantidade de motivos que ele possui no processo de aprendizagem desta língua.

Podemos classificar as pontuações dos alunos da seguinte maneira:

15 a 17 pontos = o aluno é totalmente motivado (TM)

12 a 14 pontos = o aluno é muito motivado $(\mathrm{MM})$

8 a 11 pontos $=$ o aluno é motivado (M)

4 a 7 pontos $=$ o aluno é pouco motivado (PM)

0 a 3 pontos = o aluno não possui motivação (NM)

Verifica-se neste grupo pesquisado que o grau motivacional dos alunos variam de 4 à 13 pontos, sendo o aluno A5 o participante que possui menor quantidade de motivação e o aluno A15 o participante que possui maior quantidade de motivação no aprendizado da língua japonesa. Dentro do grupo temos 2 alunos muito motivados, 9 alunos motivados, 4 alunos pouco motivados com o aprendizado da língua japonesa. 


\subsection{Análise da avaliação da aprendizagem dos alunos}

O processo de avaliação da aprendizagem dos alunos deste curso é dividido em dois momentos: o primeiro momento é realizado as avaliações das habilidades desenvolvidas nas aulas do curso e no segundo momento são aplicados duas provas em períodos bimestrais. Em ambos os momentos de avaliação, as notas são quantificadas de 0 a 10,0.

As avaliações das habilidades desenvolvidas refere-se à produção oral, produção escrita, leitura e compreensão de textos, ortoépia, compreensão auditiva e participação do aluno nas atividades. Elas são realizadas de forma constante de modo a valorizar todo o desempenho e trabalho do aluno na classe e extraclasse.

Neste contexto, os 15 alunos participantes desta pesquisa do 3ำ estágio-nível II do curso de língua japonesa, obtiveram as seguintes notas na avaliação do segundo semestre de 2012 (Quadro 2).

QUADRO 2. Notas dos alunos nas avaliações

\begin{tabular}{|c|c|c|c|c|c|c|c|c|c|c|}
\hline \multirow[b]{2}{*}{$\begin{array}{c}\text { Identificação } \\
\text { dos alunos }\end{array}$} & \multicolumn{7}{|c|}{ HABILIDADES DESENVOLVIDAS } & \multicolumn{3}{|c|}{ Provas } \\
\hline & $\begin{array}{c}\text { Produção } \\
\text { oral }\end{array}$ & $\begin{array}{c}\text { Produção } \\
\text { escrita }\end{array}$ & $\begin{array}{c}\text { Leitura e } \\
\text { compreensão }\end{array}$ & Ortoépia & $\begin{array}{c}\text { Compreensão } \\
\text { auditiva }\end{array}$ & Participação & \begin{tabular}{|c|} 
Media \\
das \\
avaliações \\
\end{tabular} & $\begin{array}{c}\text { Prova } \\
1\end{array}$ & \begin{tabular}{|c|} 
Prova \\
2 \\
\end{tabular} & $\begin{array}{c}\text { Média } \\
\text { nas } \\
\text { provas }\end{array}$ \\
\hline A1 & 7 & 8 & 8 & 8 & 9 & 8 & 8,0 & 8,0 & 8,0 & 8,0 \\
\hline $\mathrm{A} 2$ & 9 & 9 & 9 & 9 & 9 & 10 & 9,2 & 8,8 & 7,4 & 8,1 \\
\hline A3 & 8 & 9 & 8 & 8 & 8 & 8 & 8,2 & 9,3 & 6,0 & 7,7 \\
\hline A4 & 9 & 9 & 10 & 10 & 9 & 10 & 9,5 & 9,0 & 7,6 & 8,3 \\
\hline A5 & 9 & 9 & 8 & 9 & 9 & 10 & 9,0 & 8,8 & 7,2 & 8,0 \\
\hline A6 & 9 & 9 & 10 & 10 & 10 & 6 & 9,0 & 9,7 & 7,6 & 8,7 \\
\hline A7 & 9 & 9 & 9 & 9 & 9 & 10 & 9,2 & 8,4 & 7,7 & 8,1 \\
\hline A8 & 5 & 6 & 7 & 7 & 7 & 7 & 6,5 & 6,5 & 6,5 & 6,5 \\
\hline A9 & 5 & 5 & 7 & 6 & 6 & 5 & 5,7 & 5,7 & 6,8 & 6,3 \\
\hline A10 & 9 & 9 & 10 & 9 & 10 & 10 & 9,5 & 9,8 & 8,4 & 9,1 \\
\hline A11 & 9 & 9 & 9 & 9 & 9 & 8 & 8,8 & 9,5 & 8,0 & 8,8 \\
\hline A12 & 5 & 6 & 5 & 5 & 6 & 8 & 5,8 & 9,0 & 10,0 & 9,5 \\
\hline A13 & 6 & 6 & 7 & 8 & 7 & 8 & 7,0 & 7,2 & 5,6 & 6,4 \\
\hline A14 & 7 & 7 & 8 & 8 & 9 & 8 & 7,8 & 5,7 & 6,7 & 6,2 \\
\hline A15 & 10 & 10 & 10 & 10 & 10 & 10 & 10,0 & 10,0 & 10,0 & 10,0 \\
\hline $\begin{array}{c}\text { Média das } \\
\text { modalidades }\end{array}$ & 7,7 & 8,0 & 8,3 & 8,3 & 8,5 & 8,4 & & & & \\
\hline
\end{tabular}

Fonte: (Diário de classe do professor - Período: 2o semestre de 2012) 
De modo geral, verifica-se um bom desempenho dos alunos nestas avaliações, sendo 8,2 a média da turma. Nota-se que apenas 2 alunos, os alunos A9 e A12, não atingiram nota igual ou superior a 6,0 nestas avaliações. As notas deles foram 5,7 e 5,8 respectivamente.

Além das avaliações das habilidades desenvolvidas no curso, em cada semestre letivo são aplicadas duas provas escritas a cada bimestre para complementar o sistema de avaliação do aprendizado do aluno.

Nas provas escritas nota-se novamente um bom desempenho da turma (média 8,0). A média das duas provas escritas de todos os alunos participantes da pesquisa foi superior à nota 6,0 .

Quanto ao desempenho na Prova 2 em relação a Prova 1, verifica-se que 03 alunos aumentaram o desempenho na segunda prova, 03 mantiveram o desempenho e 09 alunos tiveram uma queda no desempenho da prova. O aluno $A 3$ é o que teve maior variação de desempenho entre as provas aplicadas.

Analisando a média das notas dos alunos na avaliação das habilidades e nas provas, verifica-se que o desempenho dos alunos na avaliação das habilidades é igual ou superior ao seu desempenho nas provas, sendo exceção apenas nos alunos A9 e A12 que obtiveram notas menores nas avaliações das habilidades do que nas provas bimestrais.

O caso do aluno A12 nos chama ainda mais a atenção devido a grande variação entre duas médias, a média das provas é nota 9,5 e a média das avaliações das habilidades é nota 5,8.

A média final das avaliações da aprendizagem do aluno é feita através da somatória de todas as avaliações ocorridas no semestre letivo.

Para obter a aprovação no semestre letivo, a média final do aluno deve ser igual ou superior a 6,0. Caso a nota seja inferior a 6,0 o aluno tem a oportunidade de passar por um processo de recuperação.

Apenas 1 aluno da turma, o aluno A9, precisou passar pelo processo de recuperação de aprendizagem.

\subsection{Grau de motivação $x$ desempenho no processo avaliativo da aprendizagem}

A quantidade de fatores motivacionais que o aluno possui é importante como mostra as duas extremidades da tabela, o aluno A15 possui o maior grau motivacional e possui também o maior desempenho (nota) nas avaliações, assim como, o aluno A9 que possui baixo grau motivacional e também possui o menor desempenho nas avaliações. 
No entanto, temos o aluno A3 que possui muita motivação, no entanto a classificação do seu desempenho nas avaliações está em nono lugar dentre as 15 notas da turma.

O aluno A4 que é classificado como um participante que possui poucas motivações, no entanto teve um bom desempenho nas avaliações.

\section{DISCUSSÃO}

Verifica-se neste grupo pesquisado quanto ao grau motivacional dos alunos, que não há alunos com nenhuma motivação. Tal constatação comprova a teoria de Dörnyei (2011), no qual diz que de modo geral, os alunos com suficiente motivação podem chegar ao conhecimento da língua estrangeira apesar de suas dificuldades ou aptidão. Entretanto, sem motivação o suficiente, mesmo os alunos com habilidades notáveis, não chegam ao máximo de seu potencial e não conseguem atingir metas a longo prazo.

Entre as diversas modalidades de avaliações (produção oral, produção escrita, leitura e compreensão, ortoépia, compreensão auditiva, e participação), a avaliação da produção oral dos alunos é a que possui menor média das notas $(7,7)$. A modalidade que tem o maior desempenho dos alunos é a avaliação da compreensão auditiva, com média de 8,5. Esses dados demonstram que os alunos possuem maior facilidade de ouvir e de entender o idioma do que de elaborar frases e falar a língua japonesa. Essa informação comprova a percepção da autora quanto as facilidades e as dificuldades da comunicação da língua japonesa.

Em relação ao desempenho das Provas 1 e 2, verificou-se que a maioria dos alunos tiveram uma queda no desempenho entre as provas 1 e 2. Refletindo com a professora responsável pela turma foram levantadas diversas possibilidades de causa, tais como, o alto desempenho dos alunos na prova 1 poderia estar desmotivando o aluno a estudar para a prova 2; a acumulação de conhecimento/conteúdo na prova 2 a tornaria naturalmente mais difícil que a prova 1 ; a coincidência da prova 2 com o fechamento do semestre letivo do ensino regular; entre outros fatores.

Quanto a média das notas dos alunos na avaliação das habilidades e nas provas, foram analisados os 2 alunos que obtiveram notas menores nas avaliações das habilidades do que nas provas bimestrais. Ambos os alunos apresentam alto índice de faltas nas aulas, comprometendo uma avaliação continua nas habilidades desenvolvidas dentro e fora da sala de aula.

Nota-se que para um grupo de alunos, o seu desempenho no aprendizado da língua japonesa pode estar mais voltado à qualidade (intensidade) dos fatores motivacionais do que a 
quantidade de fatores motivadores. Ou seja, o aluno pode ter poucos fatores que o motivam no processo de aprendizagem, mas a intensidade desses fatores é forte o suficiente para desencadear o seu empenho no processo de aprendizagem da língua japonesa.

Mesmo o aluno com muitos fatores motivacionais relacionados ao aprendizado é necessário o seu empenho na construção do conhecimento.

Foi analisado se nesta turma havia alguma relação entre a etnia do aluno com o seu grau motivacional e o seu desempenho nas avaliações realizadas no curso. No entanto, curiosamente nada de tendencioso foi encontrado, tal como, "os alunos descendentes de japoneses são mais motivados do que os alunos não descendentes", ou, "os alunos descendentes de brasileiros possuem menor desempenho na avaliação de aprendizagem da língua quando comparado com os descendentes de japoneses".

É importante salientar que a motivação do aluno no processo de aprendizagem pode ser considerada um fenômeno complexo e dependente de uma diversidade de fatores, inclusive conceituais que o aluno possui no momento da participação da pesquisa. Da mesma forma, é complexo o processo de avaliação da aprendizagem do aluno, pois o seu desempenho nas avaliações, traduzido e quantificado em notas, também dependem de diversas variáveis, como, físico, psicológico, cultural, entre outros influenciadores.

\section{CONCLUSÕES}

Através do estudo realizado verificou quais as relações existentes entre a motivação dos alunos no processo de aprendizagem e o seu desempenho nas avaliações realizadas.

No entanto, de modo geral, algumas observações puderam ser feitas, tal como, quantidade e a intensidade dos fatores que motivam o aluno são importantes no processo de aprendizagem dos alunos, pois de alguma forma refletem no seu desempenho nas avaliações realizadas.

Por isso considerando que há uma ligação do desempenho do aluno nas avaliações de aprendizagem em relação aos fatores que o impulsionam nesta caminhada, é de grande relevância todos os participantes deste processo conhecer o perfil motivacional do aluno para melhorar o ensino e aprendizagem dos alunos.

Neste trabalho, foi uma surpresa constatar que não há uma relação direta entre a motivação do aluno no processo de aprendizagem com sua antecedência racial, assim como, com o seu desempenho nas avaliações realizadas no curso. Desta forma, acredita-se que o aprendizado 
de uma língua estrangeira é possível para todas as pessoas independente de sua etnia, bastando querer aprender e participar ativamente da construção do seu aprendizado.

A elaboração desta pesquisa constituiu um momento de muita reflexão e melhor entendimento sobre os vários aspectos da relação existente entre os fatores motivacionais do processo de aprendizagem e o desempenho nas avaliações do curso de língua japonesa deste centro de estudo de línguas de Presidente Prudente-SP.

\section{REFERÊNCIAS}

ANDRADE, M. R. M. (Orgs). Afetividade e emoções no ensino/aprendizagem de línguas: múltiplos olhares. v.18. Campinas: Pontes Editores, 2011.

DÖRNYEI, Z. Teaching and researching motivation. 2ed. Harlow: Longman/Pearson, 2011.

GARDNER, R. C.; LAMBERT, W. E. Social psychology and second language learning: the role of attitudes and motivation. London: Richard Clay (The Chaucer Press) Ltd., 1985.

HOFFMANN, J. M. L. Avaliar para promover: as setas para o caminho. 10. ed. Porto Alegre: Mediação, 2008.

LUCKESI, C. C. Avaliação da aprendizagem escolar: estudos e proposições. São Paulo: Cortez, 2005.

SCHON, Célia Kaczarouski; LEDESMA, Maria Rita Kaminski. 2008. Avaliação da aprendizagem. Disponível em: <http://www.diaadiaeducacao.pr.gov.br/portals/pde/arquivos/2516-8.pdf>. Acessado em: 17 jan.2013.

SCHÜTZ, Ricardo. Motivação e desmotivação no aprendizado de línguas. English Made in Brasil. 2003. Disponível em: <http://www.sk.com.br/sk-motiv.html>. Acessado em: 16 abr.2012.

YIN, Robert K. Estudo de caso: planejamento e métodos. 4ed. Porto Alegre: Brookman, 2010. 